\title{
O caráter dialogal da língua por uma perspectiva instrucional da significação
}

\section{The dialogical feature of language by an instructional perspective of significance}

1 Mestranda em Letras pela PUCRS. Bolsista parcial CAPES

E-mail: mara.freitas@acad.pucrs.br
RESUMO: Segundo Ducrot (1987), a significação da frase (na língua) permite construir instruções que o interlocutor deve seguir para atribuir sentido aos enunciados (no discurso). Considerando que o sentido é uma representação da enunciação, e que a encenação enunciativa prevê um eu que se dirige a um $t u$, é evidente o caráter dialogal do discurso. Embora a língua, na qualidade de sistema de formas abstratas, não seja generosa em evidenciar esse caráter, acreditamos que ela traga, inscrito no sistema, o substrato do diálogo, devido à natureza instrucional da significação. Nossa proposta é investigar como se configuram as instruções que permitem ao interlocutor recuperar sentidos construídos pelo locutor, tomando como marco a Teoria da Argumentação na Língua (ANL), abordagem que parte do discurso para explicar a língua. Nossa metodologia prevê a análise de uma peça publicitária à luz de conceitos da ANL, objetivando evidenciar a potencialidade dialogal da língua.

PaLAVRAS-CHAVE: Língua; Dialogal; Discurso; Teoria da Argumentação na Língua.

ABSTRACT: According to Ducrot (1987), the significance of a phrase (in language) consists in instructions that the listener must follow to produce meaning to the utterance (in speech). Considering that the meaning of the utterance is a representation of its own enunciation and, in the enunciation, there is a ME that speaks to a YOU, the dialogic feature of the discourse is indubitable. Although the language is an abstract system, we believe that it has a dialogue substrate, because significance is instructional. We propose to investigate the instructions that allow the listener to recover meanings constructed by the speaker, according to the Language Argumentation Theory, an approach that uses the speech to explain the language. We intend to analyze an advertising piece according to the concepts of this theory, to evince the dialogic potentiality of language.

KEYwoRDS: Language; Dialogal; Speech; Argumentation in Language Theory. 


\section{Considerações Iniciais}

egundo Ducrot (1987:170), a significação da frase, alocada metodologicamente no plano da língua, consiste em um conjunto de instruções que especificam quais operações o interlocutor deve realizar para atribuir sentido aos enunciados, estes no plano do discurso. Considerando que o sentido é a representação da enunciação, e que a encenação enunciativa prevê um eu que se dirige a um tu, é inegável o caráter dialogal do discurso. Embora a língua, pela sua condição abstrata, não seja tão profícua em evidenciar esse caráter, acreditamos que ela traga, inscrito no próprio sistema, o substrato do diálogo, por conta da natureza instrucional da significação, cuja vocação é conduzir a ação responsiva do interlocutor. A proposta deste trabalho é investigar, mediante a análise de uma peça publicitária, como se configuram, no âmbito da significação, certas instruções que permitem ao interlocutor recuperar os sentidos construídos pelo locutor no discurso.

Optamos por analisar um anúncio comercial, pois um olhar mais atento revela que o discurso publicitário já não se restringe à enumeração das qualidades do produto para conquistar o consumidor. A propaganda de hoje não vende apenas bens e serviços; vende qualidade de vida, segurança, poder, felicidade. E a construção desses objetos conceituais, muitas vezes, não depende de uma referência à realidade empírica; ao contrário, dá-se por meio de processos de produção de sentidos com base nas relações mutuamente constitutivas que se estabelecem entre as palavras.

Nosso recorte teórico inscreve-se na Teoria da Argumentação na Língua (ANL), por tratar-se de uma perspectiva argumentativa instrucional, que parte do que o discurso expressa para explicar como a língua torna possível a produção de sentidos. Para Ducrot (2005a), a língua é essencialmente argumentativa uma vez que a significação das palavras e o sentido dos enunciados estruturam-se em pares de segmentos unidos por conectores normativos e transgressivos capazes de estabelecer uma relação de interdependência semântica entre causa e consequência.

\section{A Argumentação na Língua}

Nos Escritos de Linguística Geral, Ferdinand de Saussure (2012:30) postula que "uma forma não significa, mas vale". Essa decisão metodológica, além de inaugurar uma Linguística voltada para a noção de língua como sistema de formas interdependentes, implica a existência de outros valores [dentro do sistema] com os quais a forma, ao se confrontar, constitui o seu próprio ser a partir de um não-ser o outro.

Filiado ao pensamento saussuriano, tomando emprestadas suas noções de valor e de relação, as quais alicerçam os conceitos de signo e significado nos moldes do Curso de Linguística Geral (CLG, 2006), Oswald Ducrot edifica a Teoria da Argumentação na Língua assumindo, como hipótese externa, que o sentido de uma expressão não é resultado de sua correspondência com um referente da realidade empírica, mas é construído pela relação com outras expressões. Por essa ótica, o sentido não é dado a priori, mas construído por relações que se estabelecem entre os termos, de acordo com o que o sistema da língua prevê e permite. Considerando que as relações capazes de produzir sentido são aquelas em que os termos se articulam mediante conectores normativos ou transgressivos, a ANL conclui que a língua é essencialmente argumentativa.

Ducrot (1990) afirma que, ao nos referirmos a qualquer objeto da realidade, o que fazemos é colocá-lo em um debate entre sujeitos. Com efeito, ao nos enunciarmos diante do outro, recriamos uma realidade sob a influência da nossa subjetividade e submetemos esse recorte do real à avaliação alheia. Nesse palco enunciativo, em que se confrontam as representações de mundo de um sujeito locutor (EU) e de um sujeito interlocutor (TU), percebemos 
que o diálogo é a modalidade de interação por excelência. Cabe ao locutor fornecer as instruções para que o interlocutor recupere o sentido do que foi enunciado, ou seja: uma imagem da própria enunciação. Tais instruções, contudo, não são de caráter aleatório, mas se estruturam por meio do que a ANL denomina encadeamentos argumentativos.

Antes de abordar os encadeamentos argumentativos, porém, é preciso que nos atenhamos a uma delimitação de campos essencial para compreender a ANL: língua/frase/significação de um lado, discurso/enunciado/sentido de outro. Na baliza da metodologia saussuriana, que planifica duplamente língua e fala, Ducrot (1980) define palavra (e frase) como uma abstração no plano da língua, uma entidade portadora de significação segundo as regras do sistema linguístico; e enunciado como a realização concreta e singular de uma frase por meio da enunciação, o qual ganha sentido no plano do discurso. Por essa perspectiva, a mesma frase pode ser enunciada mais de uma vez, cada uma delas por um enunciado diferente. Todavia, ainda que metodologicamente distintos, significação e sentido são indissociáveis.

\subsection{Os encadeamentos argumentativos}

Os encadeamentos argumentativos, ou argumentações, constituem a estrutura básica tanto da significação das palavras quanto do sentido dos enunciados. Cada encadeamento é composto por um termo antecedente e por um consequente, ambos articulados por um conector discursivo. Cada um dos termos, também denominados respectivamente suporte e aporte, pode apresentar-se como uma única palavra ou como expressões complexas. O conector, por sua vez, pode ser normativo (do tipo portanto e afins), ou transgressivo (do tipo no entanto e afins).

Ao longo deste artigo, nos exemplos e nas análises, adotaremos a nomenclatura abreviada do francês: DC para donc (portanto) e PT para pourtant (no entanto). Além disso, convencionaremos $A$ para representar o termo antecedente e $B$ para o termo consequente.

Consideremos o exemplo:

(a) Joana só aceitou casar-se com Pedro quando viu o tamanho da fortuna dele.

Admitamos que subjaza ao enunciado o encadeamento argumentativo:

(a') Pedro é rico DC Joana casa-se com ele

Trata-se de um encadeamento argumentativo cujo termo antecedente é Pedro é rico e o termo consequente é Joana casa-se com ele. A argumentação normativa que se estabelece entre os termos, marcada pelo conector DC (portanto), constrói um sentido: Joana é uma pessoa interesseira quando se trata de casamento.

Observemos outro exemplo:

(b) Mesmo Pedro sendo rico, Joana aceitou seu pedido de casamento.

Tomemos como subjacente o encadeamento:

(b') Pedro é rico PT Joana casa-se com ele

Da mesma forma que a', esse encadeamento tem como termo antecedente Pedro é rico, e como consequente Joana casa-se com ele; mas agora é empregado o conector PT (no entanto). É interessante observar como o sentido muda, como a conexão transgressiva constrói para b' um sentido totalmente diferente: Joana prefere um marido que não seja rico (apesar de fazer uma concessão a Pedro).

Convencionando que Pedro é rico corresponde a $A$ e que Joana casa-se com ele corresponde a $B$, podemos formalizar os encadeamentos por: $A D C$ $B$ e $A P T B$. Essa formalização permite melhor visualizar um ponto essencial ao domínio da ANL: quando nos referimos a "construir sentido", não se 
trata de construir um sentido autônomo para A e outro para B. Trata-se de construir um sentido único que abrange $A$ em relação a $B$, um sentido $A-D C$ - $B$ ou $A$-PT-B. $O$ sentido então produzido não sobrevive fora dessa relação em particular.

Uma vez formalizados os exemplos anteriores, não é difícil perceber que a significação é mais do que um atributo de um objeto da realidade empírica, de antemão estabelecido e pleno. Pelo contrário, existe, nas palavras e frases, uma fração de incompletude que carece da relação com outras frases e palavras para construir sentidos. Ou seja, o sentido de um enunciado é fruto de uma relação de mútua dependência entre seus segmentos, cuja orientação é expressa pelo conector. Essa noção de interdependência semântica alicerça a atual fase da ANL, desenvolvida por Marion Carel juntamente com Ducrot, denominada Teoria dos Blocos Semânticos - TBS.

\subsection{A interdependência e o bloco semântico}

Segundo Ducrot (2004), o sentido do enunciado, realizado individualmente, constitui-se pelos discursos que as palavras ou expressões autorizam. Assim, nem todas as continuações são permitidas como normas da língua, visto que esta é um sistema de formas compartilhadas, alocado por Saussure (CLG, 2006) no eixo social. Assumindo que a continuação discursiva obedece ao que a língua permite, o marco da TBS postula que os encadeamentos argumentativos ganham sentido por uma relação de interdependência semântica entre seus constituintes; em outras palavras, o sentido depende das relações linguisticamente possíveis entre os termos.

Confrontemos os encadeamentos argumentativos:

(a') Pedro é rico DC Joana casa-se com ele

(b') Pedro é rico PT Joana casa-se com ele
O encadeamento a' representa um casamento realizado por interesse financeiro, constituindo Joana como uma pessoa materialista, interesseira. Já no encadeamento b', percebemos Joana como alguém que rechaça o materialismo quando se trata de casamento. É fácil perceber, aqui, que são construídos sentidos completamente distintos conforme empregamos um DC ou um PT mesmo entre segmentos idênticos, o que evidencia o papel decisivo do conector para a interdependência semântica.

Por outro lado, a interdependência semântica pode permanecer inalterada ainda que troquemos o conector. É o caso da negação Pedro é rico PT Joana não se casa com ele, cuja representação de uma Joana interesseira ainda é a mesma que em a'. Quando a interdependência se mantém, a despeito da negação de um ou dos dois segmentos encadeados, estamos diante do que a TBS denomina bloco semântico.

Todo bloco semântico, por marcar uma interdependência em particular (e portanto um sentido em particular), apresenta quatro possibilidades de combinação dos segmentos, as quais correspondem ao que a TBS trata por aspectos. Seguindo nossa convenção, para um bloco semântico normativo, temos os aspectos:

- A DC B

- A PT neg B

- Neg A PT B

- Neg A DC neg B

Os blocos semânticos transgressivos apresentam os aspectos:

- A PT B

- A DC neg B

- Neg A DC B

- Neg A PT neg B 
(a') Pedro é rico DC Joana casa-se com ele

\begin{tabular}{|l|l|}
\hline \multicolumn{2}{|c|}{ Aspectos e Encadeamentos do bloco semântico Joana é interesseira } \\
\hline A DC B & Pedro é rico PORTANTO Joana casa-se com ele. \\
\hline A PT neg B & Pedro é rico NO ENTANTO Joana não se casa com ele. \\
\hline neg A PT B & Pedro não é rico NO ENTANTO Joana casa-se com ele. \\
\hline neg A DC neg B & Pedro não é rico PORTANTO Joana não se casa com ele. \\
\hline
\end{tabular}

O quadro anterior ilustra as diferentes possibilidades de combinação dos segmentos encadeados, conforme o sentido que pretendemos construir. Partindo do aspecto normativo $A D C B$, podemos negar ambos os segmentos, mantendo o conector (neg A DC neg B); podemos negar apenas o primeiro segmento, invertendo o conector para transgressivo (neg A PT B); ou podemos negar apenas o segundo segmento, invertendo o conector para transgressivo (A PT neg B). Essas combinações, todavia, não são gratuitas; pelo contrário, elas estabelecem relações decisivas para a argumentação.

- Relação de conversão: consiste em negar o segundo segmento e inverter o conector. O sentido produzido pela conversão, ao "manter a causa e negar a consequência", é o de negação simples, ou seja, reconhecer a causa, mas se opor a ela:

\begin{tabular}{|l|l|}
\hline A DC B & Pedro é rico PORTANTO Joana casa-se com ele. \\
\hline A PT neg B & Pedro é rico NO ENTANTO Joana não se casa com ele. \\
\hline
\end{tabular}

Os aspectos são sempre conversos entre si.

- Relação de reciprocidade: consiste em negar ambos os segmentos, mantendo o conector. Ao negar tanto a causa quanto a consequência, a reciprocidade produz um efeito de "contrário".

\begin{tabular}{|l|l|}
\hline A DC B & Pedro é rico PORTANTO Joana casa-se com ele. \\
\hline neg A DC neg B & Pedro não é rico PORTANTO Joana não se casa com ele. \\
\hline
\end{tabular}

Os aspectos são sempre recíprocos entre si.

- Relação de transposição: consiste em negar o primeiro segmento, invertendo o conector. Ao negar a causa e inverter a conexão, a transposição confere certa "elasticidade" à consequência mantida, abrindo espaço para causas além daquela originalmente posta no encadeamento. Essa relação produz um efeito de gradualização, ou seja, o sentido do bloco permanece o mesmo, porém com nuances "para mais" ou "para menos". No caso de nosso exemplo, Joana pode ser apresentada como interesseira em maior ou menor grau.

\begin{tabular}{|l|l|}
\hline A DC B & Pedro é rico PORTANTO Joana casa-se com ele. \\
\hline neg A PT B & Pedro não é rico NO ENTANTO Joana casa-se com ele. \\
\hline
\end{tabular}

Os aspectos são sempre transpostos entre si.

\subsection{A Argumentação Externa e a Argumentação Interna}

Uma vez assumindo que a argumentação na língua se configura, tanto a significação quanto o sentido, mediante encadeamentos argumentativos, Ducrot (2005c) chama a atenção para duas formas pelas quais uma entidade linguística vincula-se ao sentido: a argumentação externa e a argumentação interna.

\subsubsection{A Argumentação Externa}

A argumentação externa (AE) de uma entidade linguística consiste nos encadeamentos dos quais essa entidade é um dos termos, seja o 
antecedente, seja o consequente. Isso leva a dizer que a $\mathrm{AE}$ corresponde aos diferentes sentidos construídos conforme a posição que a entidade ocupa no encadeamento.

Observemos a expressão Pedro é rico nos seguintes enunciados e em suas respectivas argumentações externas:

\section{AE à direita:}

(c) Pedro ficou rico ao acertar sozinho na loteria.

(c') Pedro acertou na loteria DC Pedro é rico.

$\mathrm{AE}$ à esquerda:

(d) Joana vai se casar com Pedro, afinal ele é rico.

(d') Pedro é rico DC Joana casa-se com ele.

Em c', Pedro é rico representa o termo consequente, o que configura uma $\mathrm{AE}$ à direita. Em d', a expressão está na posição de termo antecedente, configurando uma $\mathrm{AE}$ à esquerda. A diferença, contudo, não se resume à geografia do encadeamento; o posicionamento da entidade na $\mathrm{AE}$ é determinante para o sentido. Em uma AE à direita, a argumentação converge para a entidade analisada, pois esta é apresentada como uma consequência. Já em uma $\mathrm{AE}$ à esquerda, a argumentação decorre da entidade, esta sendo apresentada como causa. Posicionar uma entidade como causa ou como consequência em uma argumentação interfere na continuação discursiva, impactando inclusive no bloco semântico. Em c' Pedro é rico corresponde ao bloco semântico de um dos efeitos de se acertar na loteria (evidentemente em outro enunciado, ao ganhar na loteria, nosso personagem poderia ter ficado feliz ou preocupado ou mesmo ter sucumbido a um ataque cardíaco...). Por outro lado, em d' a mesma entidade pertence ao bloco das razões para Joana casar-se (sendo ela uma pessoa interesseira como apresentado no enunciado). Considerando que o sentido do enunciado é a representação da enunciação, não podemos negar que estamos diante de instruções distintas, que suscitam respostas distintas do interlocutor.

Outra peculiaridade da AE é apresentar-se em pares de aspectos conversos. Retomemos a AE de Pedro é rico no encadeamento Pedro é rico DC Joana casa-se com Pedro, formalizando Joana casa-se com Pedro como A e Pedro é rico como B:

\begin{tabular}{|l|l|}
\hline A DC B & Pedro é rico PORTANTO Joana casa-se com Pedro \\
\hline A PT neg B & Pedro não é rico NO ENTANTO Joana casa-se com Pedro \\
\hline
\end{tabular}

Pelo quadro anterior, é possível perceber que, apesar da negação, a interdependência semântica não se altera: em ambos os aspectos, a riqueza de Pedro é a causa de Joana casar-se com ele, e o bloco semântico continua constituindo Joana como uma pessoa interesseira.

\subsubsection{A Argumentação Interna}

A Argumentação Interna (AI) nada mais é do que um encadeamento que parafraseia a entidade linguística. Em outras palavras, a AI responde à pergunta: o que isso quer dizer. Por ser uma paráfrase, a AI não contém, em nenhum de seus segmentos, a entidade descrita (pelo menos não completamente).

Tomemos como entidade linguística a analisar a palavra interesseira, qualidade atribuída à nossa personagem Joana em relação ao seu casamento com Pedro. Como podemos parafrasear tal palavra? O que quer dizer uma pessoa interesseira senão aquela que faz o possível para obter vantagem? Nesse caso, uma AI bastante aceitável é o encadeamento obter vantagem DC fazer.

Ao contrário da $\mathrm{AE}$, a $\mathrm{AI}$ não contempla aspectos conversos, pois a negação provocada pela operação de conversão altera a interdependência, 
desintegrando o bloco semântico. Não esqueçamos que a AI do adjetivo interesseira pode conter o aspecto obter vantagem DC fazer; mas jamais o aspecto converso obter vantagem PT não fazer.

Ainda do ponto de vista dos aspectos, a AI contempla os recíprocos, o que permite afirmar que o sentido interno de uma entidade prevê o seu contrário, sem que se quebre a interdependência semântica. A AI de interesseira pode ser assim formalizada:

\begin{tabular}{|l|l|}
\hline A DC B & Obter vantagem DC fazer \\
\hline neg A DC neg B & Não obter vantagem DC não fazer \\
\hline
\end{tabular}

\section{A Análise}

Uma vez delineado o recorte teórico, passamos à análise de uma peça publicitária da empresa de telefonia Tim, assumindo como hipótese que a língua possui uma potencialidade dialogal passível de ser apreendida pelas instruções inerentes à argumentação.

Partindo do discurso em sua materialidade, nossa metodologia busca examinar de que forma, no plano da língua, as orientações para determinadas continuações discursivas inerentes aos signos linguísticos permitem construir instruções para a produção de sentidos. Para tanto, o primeiro passo consiste em identificar os encadeamentos argumentativos subjacentes aos enunciados, no âmbito da argumentação interna e externa, descrevendo os aspectos normativos e transgressivos em suas relações de conversão, reciprocidade ou transposição. Uma vez descritos os aspectos, analisaremos a interdependência semântica a eles subjacente, apontando quais instruções são forjadas no nível desses blocos semânticos, capazes de possibilitar ao interlocutor recuperar os sentidos produzidos pelo locutor.

\subsection{Peça publicitária analisada ${ }^{12}$}

Imagine viver sem fronteiras. Poder estar sempre perto de quem você gosta. Mesmo daqueles amigos mais distantes. Imagine poder ir a qualquer lugar. E até estar em dois lugares ao mesmo tempo. Não ter limites. Não ver distâncias. Esse jeito de viver existe, basta usar o seu celular.

\subsection{Análise dos encadeamentos que subjazem ao sentido do discurso}

a) Imagine poder estar [perto], imagine poder ir [a qualquer lugar] e imagine poder estar [em dois lugares ao mesmo tempo] evocam, como pressuposto, o encadeamento transgressivo querer PT neg poder. Esse encadeamento corresponde à Argumentação Interna da palavra limite, permitindo tomá-la como significação de fronteira no enunciado Imagine viver sem fronteiras.

b) 0 encadeamento transgressivo viver PT neg ter limites caracteriza a Argumentação Interna de Viver sem fronteiras. A interdependência entre os termos remete a um bloco semântico que tem como aspecto converso viver $\boldsymbol{D C}$ ter limites, correspondente a mais um pressuposto.

c) Em Imagine viver sem fronteiras, o verbo imaginar, cuja Argumentação Interna pode ser tomada por não é PT pode ser, empregado no Modo Imperativo e articulado a viver PT neg ter limites, permite constituir um interlocutor que acredita em uma vida com limitações [viver $\boldsymbol{D C}$ ter limites] e um locutor que o provoca a transgredir essa crença.

d) Subjazem ao enunciado Poder estar sempre perto de quem você gosta. Mesmo daqueles amigos mais distantes os encadeamentos normativos gostar de alguém DC querer estar junto e distância DC ter limite.

${ }^{12}$ Anúncio veiculado pela Revista Veja, edição maio/2004. Disponível em: http://www.propagandaemrevista com.br/propaganda/6384/. Acesso em 20/05/2015. 
e) Em Poder estar sempre perto de quem você gosta, o advérbio sempre evoca a Argumentação Externa expressa pelos aspectos recíprocos sempre DC satisfatório e neg sempre DC neg satisfatório. A relação de reciprocidade, cujo efeito é confrontar opostos, carrega as instruções latentes para construir um sentido positivo: estar perto todo tempo.

f) Em Imagine poder ir a qualquer lugar, o adjetivo indefinido qualquer contém instruções para construir uma positividade: estar em lugares independentemente da natureza deles. Uma vez mais, o que subjaz é a relação de reciprocidade evocada pela Argumentação Externa, agora expressa pelos aspectos qualquer lugar DC satisfatório e neg qualquer lugar DC neg satisfatório.

g) Em $E$ até estar em dois lugares ao mesmo tempo, o advérbio até é a base sobre a qual se constrói a Argumentação Interna um único tempo PT neg um único lugar, cujo aspecto converso é um único tempo DC um único lugar. Essa relação de conversão é o que dá sustentação ao pressuposto de que só se pode estar em um lugar de cada vez.

h) Em Não ter limites. Não ver distâncias, ressurge a Argumentação Externa da palavra distância, expressa pelos aspectos recíprocos distância DC limite e neg distância DC neg limite.

i) Em Não ter limites. Não ver distâncias. Esse jeito de viver existe, basta usar o seu celular, é possível confrontar dois encadeamentos neg distância DC neg limite e celular DC neg distância. Como resultado, temos o bloco semântico expresso pelo encadeamento celular DC neg limite.

Muito embora outros encadeamentos possam ser depreendidos da peça analisada, abrangendo nuances que aqui não foram prestigiadas, acreditamos que o inventário a seguir nos fornece uma espécie de coluna dorsal capaz de dar conta das instruções mais relevantes para a construção de um sentido global do anúncio.

\begin{tabular}{|r|c|l|}
\hline querer & PT & neg poder \\
\hline viver & PT & neg ter limites \\
\hline viver & DC & ter limites \\
\hline não é & PT & poder ser \\
\hline gostar de alguém & DC & querer estar junto \\
\hline distância & DC & ter limite \\
\hline sempre & DC & satisfatório \\
\hline neg sempre & DC & neg satisfatório \\
\hline qualquer lugar & DC & satisfatório \\
\hline neg qualquer lugar & DC & neg satisfatório \\
\hline um único tempo & PT & neg um único lugar \\
\hline um único tempo & DC & um único lugar \\
\hline neg distância & DC & neg limite \\
\hline celular & DC & neg distância \\
\hline celular & DC & neg limite \\
\hline
\end{tabular}

Comparando os enunciados aos encadeamentos argumentativos, é possível perceber que os encadeamentos em si não são enunciados, mas operam em um nível subjacente ao da enunciação, fornecendo instruções para que o interlocutor recupere, passo a passo, o percurso semântico que o locutor pavimentou, partindo de um desejo de viver sem limites e chegando a uma possibilidade de realizar esse desejo utilizando um celular. As argumentações internas e externas, os aspectos expressos e as relações de conversão e reciprocidade entre eles, os pressupostos evocados, enfim todo o tecido argumentativo que reveste o discurso é efetivamente trançado no nível das permissões e proibições inscritas na significação (no plano da língua). 


\section{Considerações Finais}

Ponderando que a distinção entre discurso e língua é essencialmente metodológica, situamos na língua as instruções que lastreiam a construção do sentido, não obstante este pertença à instância da enunciação, dela emergindo singular a cada enunciado. Embora seja na instância discursiva que o EU/locutor se instala como tal, e instaura o TU/interlocutor de quem espera sempre uma resposta, é da língua que são pinçadas as formas que marcam, e em certa medida instituem, um e outro. Embora as argumentações interna e externa sejam evocações do discurso, a interdependência semântica efetiva-se no nível dos aspectos, que nada mais são do que a significação enquanto possibilidades de combinação e orientações para a continuidade discursiva (seja normativa, seja transgressiva). Nada se manifesta volitiva e individualmente no discurso sem que tenha emergido do sistema de valores socialmente compartilhados que é a língua, sob a forma de instruções para a atividade responsiva do outro. Se a peça publicitária aqui analisada pode ser encenada como um diálogo entre dois sujeitos que comungam do desejo de viver sem limites, em que o locutor acredita que isso é possível utilizando um telefone celular, e orienta o interlocutor a responder na mesma medida, tal organização enunciativa não está explícita senão por marcas que subjazem ao dito. Trazer à tona o substrato dialogal inerente à língua é o que acreditamos ter realizado ao final da análise.

Extrapolando, por fim, o objeto desta pesquisa, chamamos a atenção para um traço dialogal peculiar que observamos em nossas análises: a relação de reciprocidade nas $\mathrm{AE}$, ao focalizar o aspecto contrário de uma argumentação (como em distância DC limite versus neg distância DC neg limite), atrai o olhar do interlocutor para a possibilidade de uma mudança de comportamento, de atitude em relação a seu estilo de vida. A sutileza dessa instrução parece-nos especialmente pródiga ao discurso publicitário, muito embora não nos permitamos mais do que especular por ora, deixando essa abordagem interdisciplinar em suspenso, para uma futura reflexão.

\section{Referências}

DUCROT, Oswald. Análise de textos e linguística da enunciação. In: DUCROT, Oswald et al. As palavras do discurso. Paris: Minuit, 1980

Esboço de uma teoria polifônica da enunciação. In: DUCROT, Oswald. $O$ dizer e $o$ dito. Campinas: Pontes, 1987, p. 161-218.

. Primera conferencia. In DUCROT, Oswald. Polifonía y argumentación. Cali: Universidad del Valle, 1990, p. 49-64.

Sentido y argumentación. Trad. María Marta Negroni. In: ARNOUX, Elvira; NEGRONI, María Marta García. Homenaje a Oswald Ducrot. Buenos Aires: Eudeba, 2004 p. 359-370.

Introducción - Conferencia 1. Trad. María Marta Negroni e Alfredo Lescano. In: CAREL, Marion; DUCROT, Oswald. La semántica argumentativa: una introducción a la teoría de los bloques semánticos. Buenos Aires: Colihue, 2005aㅗ p. 11-25.

. Los bloques semánticos y el cuadrado argumentativo - Conferencia 2. Trad. María Marta Negroni e Alfredo Lescano. In: CAREL, Marion; DUCROT, Oswald. La semántica argumentativa: una introducción a la teoría de los bloques semánticos. Buenos Aires: Colihue, 2005b, p. 29-50.

Argumentación interna y argumentación externa - Conferencia 3. Trad. María Marta Negroni e Alfredo Lescano. In: CAREL, Marion; DUCROT, Oswald. La semántica argumentativa: una introducción a la teoría de los bloques semánticos. Buenos Aires: Colihue, 2005c. p. 53-89.

SAUSSURE, Ferdinand de. Curso de Linguística Geral. São Paulo: Cultrix, 2006.

Sobre a essência dupla da linguagem. Trad. Carlos Augusto Salum e Ana Lucia Franco. In: Escritos de Linguística Geral. São Paulo: Cultrix, 2012. p. 19-80.

Recebido em 05/11/2015

Aceito em 29/12/2015. 